\title{
DAC Peer Review의 소개와 원조평가
}

박 숙 현 (KOICA 평가실 과장)

\section{목 차}

1. 들어가며

2. DAC Peer Review, 그리고 평가

3. $\mathrm{KOICA}$ 의 평가현황

4. 이슈 및 향후과제

5. 시사점 및 결론

\section{1. 들어가며}

2012년 한국은 가입 후 첫 공식 DAC Peer Review를 받고 있으며, 지난 6월은 정부의 메모 랜덤 제출과 함께 DAC Peer Review팀의 현장실사까지 마무리한 상태이다. 금번 DAC Peer Review와 현장실사 방문을 계기로 한국 ODA 관련 부처, 수행기관, 시민사회 등은 지난 2008 년 특별검토 이후 진전사항 및 개선사항을 면밀히 검토하고 재정비하게 되었다고 할 수 있다. 평가분야 또한 제도, 체계, 현황, 향후 방향 등을 종합적으로 진단하게 되었다. 메모랜덤에 의하 면 여러 측면에서 $\mathrm{ODA}$ 의 평가분야는 괄목할만한 변화를 이룬 것으로 자체진단을 하고 있다. 본 글은 $\mathrm{KOICA}$ 측면에서 준비해 온 평가분야의 여러 현황과 이슈를 공유하고자 하며, 앞으로 보다 나은 DAC Peer Review의 대비를 위한 준비사항들을 논의하고자 하며 주요 목적은 아래 와 같다. 
- DAC Peer Review의 평가관련, 요구사항 및 점검사항을 살펴본다.

- $\mathrm{KOICA}$ 의 현황과 체계를 진단한다.

- 향후 준비사항을 점검한다.

\section{DAC Peer Review, 그리고 평가(Evaluation)}

DAC Peer Review는 매 4 5년 마다 수검국들의 개발협력관련 전반적인 사항을 점검하고 개선방향을 모색하는 $\mathrm{OECD} / \mathrm{DAC}$ 의 공식절차이다. 한국은 올해 첫 DAC Peer Review를 받 고, 4년 후인 2016년 제2차 DAC Peer Review를 받게 될 것이다. 그 과정에서 다른 수검국의 $\mathrm{DAC}$ Peer Review에 참석해야하는 의무도 갖게 된다. 그렇다면 DAC Peer Review 주요 목 적은 무엇인가? DAC에서 제공하는 안내서에 따르면 DAC Peer Review는 아래와 같은 목적 으로 실시되고 있다.

“The objectives of DAC Peer Reviews are to ; monitor members' development co-operation and humanitarian aid policies and programmes and assess their progress against the goals and policies agreed in the DAC as well as internationally and nationally established objectives;... 중략....Peer Reviews assess the prformance of a given member country, not just that of its aid agency and exame both policy and implementation. They take an integrated, system-wide perspective on the development and humanitarian aid activities of the country under the review"

수검국의 법적기반, 정치적 공약, 비젼 및 전반적인 조직을 포함하여 수검대상국의 개발 협력을 형성하는 정치적 지침, 정책 및 전략을 살펴본다. 또한 원조 및 개발협력에 대한 지 원 및 이에 대한 대중의 인식 정도, 그리고 국내 책임성 이슈를 검토한다. 시스템의 변화를 파악하기 위해 이전 동료심사에서 제시된 $\mathrm{DAC}$ 의 권고사항을 어떻게 이행하였는가를 파악 한다. 1)

1) OECD/DAC, 2010, DAC PEER REVIEW CONTENT GUIDE 
앞의 정의에서 살펴본 바와 같이 DAC Peer Review에서 중점을 두고 보는 사항은 원조를 둘 러싼 주변의 제반여건과 환경들이다. “평가”라는 세부항목을 점검하더라도 궁극적으로는 평가 를 효과적으로 수행하게 만드는 환경, 주변여건, 체계, 국제적 원칙에 부합 여부 등을 중심으로 살펴본다는 의미이다.

구체적으로 DAC Peer Review에서 모니터링 및 평가에 해당하는 부분은 “원조를 넘어선 개 발(Development Beyond Aid)", “조직과 관리(Organizations and Management)", “원조 효과성 및 성과(Aid Effectiveness and Results)"의 카테고리에서 점검된다고 할 수 있다. "원조를 넘어선 개발(Development Beyond Aid)" 은 회원국가들이 원조 프로그램을 넘어서 정 책일관성을 추진하는지를 살펴보는 세션이며, 제도적 구조의 효율성을 마련하기 위한 절차들, 인센티브 제공여부, 국민들을 대상으로 투명한 결과보고가 진행되는가를 살핀다. 현지차원의 이슈들에서는 수검국이 협력대상국의 정부, 시민사회 및 현장사무소 직원으로부터 증거와 견해 를 수집하고, 현장사무소 직원들이 이러한 방향으로 장려되는지 여부를 묻는다.

“원조효과성 및 성과(Aid Effectiveness and Results)" 세션은 국제적으로 선언한 공약들 (예: MDGs, $\mathrm{PD}, \mathrm{DAC}$ principles 등)의 이행여부를 주로 검토하고, 개발협력 기관들이 보다 더 효과적인 원조관리 및 수행에 얼마나 모니터링 및 평가를 통해 학습기능을 강화하고 개선하 고자 하는지를 살펴본다.

“조직과 관리(Organizations and Management)” 세션에서는 원조정책을 구체적이고 효과 적으로 실행할 수 있는 기관의 역량, 행정구조, 절차, 시스템을 집중적으로 점검한다. 평가내용 이 조직적 관점에서 어떻게 이루어지고 있는지 가장 깊이 있게 살펴보고 있다. 이 세션에서는 개발성과관리(Management for Development Results), 성과입증(Demonstrating results), 효율성 및 행정비용(Efficiency and Administrative costs), 평가(Evaluation)로 보다 세부적으로 구분되어 있다. 본 글에서 집중적으로 다루는 부분은 “조직과 관리 (Organizations and Management)" 의 평가(Evaluation) 세부항목이다. 즉 KOICA의 평가 (Evaluation)에 관한 소개이다.

조직과 관리의 평가와 관련한 질문들은 아래와 같이 구분된다. 


\begin{tabular}{|c|c|}
\hline 구분 & 상세질문 \\
\hline $\begin{array}{l}\text { 투명성과 책임성 } \\
\text { (Transparency and } \\
\text { Accountability) }\end{array}$ & $\begin{array}{l}\text { 공여국의 평가 정책은 무엇인가? 평가가 조직 내에 어떻게 알려져 } \\
\text { 있으며, 평가 문화는 어떻게 장려되고 있는가? 평가 계획에 있어 } \\
\text { 우선순위를 확인하는 주체는 누구이며, 어떻게 확인하고 있는가? } \\
\text { 평가 절차는 어느 정도로 조직과 정치적 영향력으로부터 독립적인 } \\
\text { 가? 평가 절차는 독립적 관찰자들에 의해 공신력 있고, 타당하다고 } \\
\text { 인정받고 있는가? DAC Quality Standards for Evaluation은 어 } \\
\text { 떻게 활용되고 있는가? 평가 결과들은 지속적으로 공개되고 있는 } \\
\text { 가? 평가에 대한 경영진의 대응(management response)은 어떠 } \\
\text { 하며, 후속조치는 어떻게 구성되어 있는가? 역량개발 지원에서 성 } \\
\text { 취하고자 하는 성과들(intended outcomes)은 어떻게 모니터링, } \\
\text { 측정 및 평가되고 있는가? }\end{array}$ \\
\hline 자원(Resources) & $\begin{array}{l}\text { 재정 및 인적 자원들은 평가 목표치 달성을 위하여 적절하게 확보 } \\
\text { 되어 있는가? 담당 기관은 어느 정도로 공동평가를 장려하고 참여 } \\
\text { 하고 있는가? 또한 평가에 있어 DAC 평가 네트워크, 타 기관들의 } \\
\text { 평가, 공동평가 혹은 협력대상국 주도 평가들로부터 어느 정도의 정 } \\
\text { 보를 활용하고 있는가? }\end{array}$ \\
\hline 학습(Learning) & $\begin{array}{l}\text { 담당 기관 내외부에서 평가 결과의 주된 활용자는 누구이며, 동 평 } \\
\text { 가 결과를 통해 무엇을 학습하는가? 평가 결과 및 권고사항들은 정 } \\
\text { 책 형성 및 프로그램 계획 · 실행에 영향을 미치고 있는가? 평가결 } \\
\text { 과는 향후 경영 툴(a forward looking management tool)로 활용 } \\
\text { 되고 있는가? }\end{array}$ \\
\hline
\end{tabular}




\section{3. $\mathrm{KOICA}$ 의 현황}

$\mathrm{KOICA}$ 의 평가기능은 1996 년부터 시작, 2006년 별도의 사업평가팀 신설, 2011년 평가실 독 립 등다년간에 걸쳐 강화되었다고 할 수 있다. 2012년 현재 DAC Peer Review의 평가부문 주 요 진전사항은 별도의 평가정책 수립에서부터 환류기능까지 다양하게 나타다고 있으며, 구체적 인 내용은 다음과 같다.

\section{평가정책 및 DAC 평가네트워크(Evalnet)}

모니터링과 평가의 기능은 궁극적으로 원조효과성과 개발성과 달성을 위해 필요한 기능이고, 이를 조직차원에서 전략적으로 활용하고 방향을 설정하는 작업이 바로 평가정책이라고 할 수 있다. 2010년 OECD/DAC회원국을 대상으로 발간한 「Evaluation in Development Agencies」에 의하면, 회원국 평가정책이 평균적으로 포함하는 내용들은 아래 표와 같다.

\section{Figure 2.1. Content of evaluation policies - percentage of members whose evaluation policy contains directions on:}

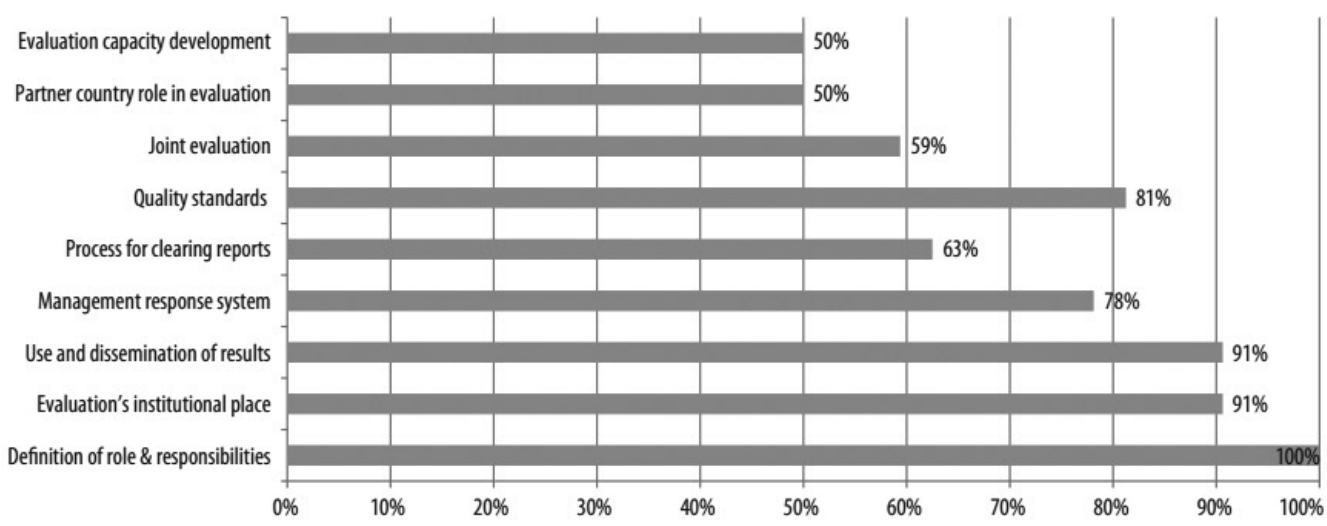

평가정책의 주요 내용은 수원국의 평가역량강화(Evaluation Capacity Development), 평 가에서의 수원국 역할, 공동평가, 평가품질관리, 보고서 관리, 경영진의 평가결과 대응체계, 평 가결과의 환류 및 활용, 평가 관련팀의 조직적 위치와 역할 등을 포함하고 있다. $\mathrm{KOICA}$ 의 경우 2011-2013년 평가중기전략을 수립하여 단기적으로는 평가자체의 품질향상으로 신뢰성을 높이 고, 장기적으로는 활발한 학습과정과 책임성 강화에 기여한다는 목적으로 추진 중이다. 특히 전 략기간 동안 역점을 두고 개선하려는 과제는 평가품질관리, 환류, 평가 역량강화 부분이다. 
【KOICA 평가중기전략(2011-2013)】

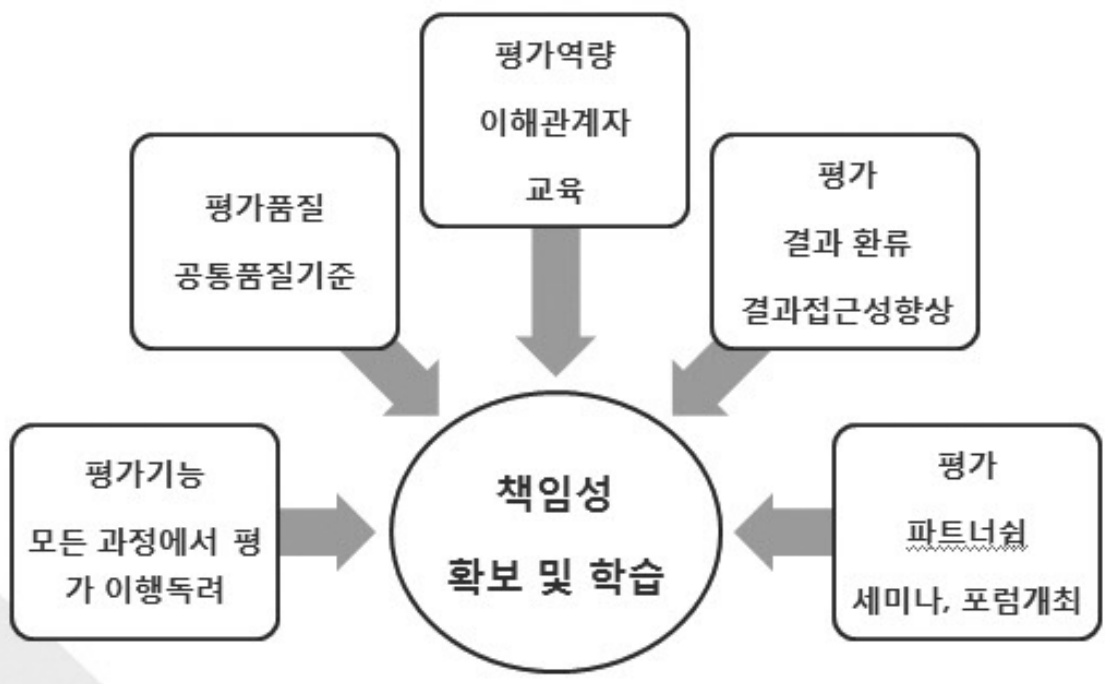

$\mathrm{KOICA}$ 는 $\mathrm{DAC}$ 가입 이후 지속적으로 $\mathrm{DAC}$ 평가네트워크에 참여 (총4회), 개발평가 이슈공 유와 함께 논의된 내용을 토대로 다양한 시도를 추진하였다. 2010년도 DAC 평가네트워크 참 석 이후 영향평가 실시, 수원국 공동평가실시, 범분야(젠더 및 환경)이슈 평가기준 적용 등을 추 진하여 왔다. 특히 2012년도에는 대외적으로 DAC 평가네트워크 이슈공유를 위한 개발평가세 미나를 개최하여, 타 회원국의 사례소개와 함께 네트워크에서 논의되는 새로운 방법론 소개 등 을 공유하였다. DAC 평가네트워크에서 논의된 평가흐름, 이슈, 방향 등을 파악하여 국내에 시 범적으로 적용하고 소개함으로써 국내 ODA 관련 평가자들의 이해도를 향상시킬 수 있다는 점 에서 유용하였다.

\section{평가품질관리}

$\mathrm{KOICA}$ 는 $\mathrm{DAC}$ 개발평가품질기준2)을 근간으로, 보다 $\mathrm{KOICA}$ 의 평가수행절차에 적합한 평 가품질관리기준을 수립하였다. 중기전략에 의거하여, 2011년도부터 평가품질관리 기준을 평가 용역 계약시 의무적으로 포함시켜 평가수행 전반은 물론, 최종평가보고서 심사 시 평가수행팀 이 기준을 숙지하고 자가 점검하도록 유도하였다. 2012년도 부터는 「사업평가 시행세부지침 내 평가품질관리기준」을 규정화하고 모든 평가에 적용, 평가설계의 타당성, 평가수행의 일관성 및 투명성, 평가결과의 신뢰성을 기준으로 총 11 개 세부관리 항목과 44 개의 세부점검 요소를 마련 하였다. 


\section{【KOICA 평가품질관리 기준 요약】}

\begin{tabular}{|c|c|c|}
\hline 품질관리 기준 & 평가 절차 & 세부 관리 항목 \\
\hline $\begin{array}{l}\text { 평가설계(Design)의 } \\
\text { 타당성(Relevance) }\end{array}$ & 설계 단계 & $\begin{array}{l}\text { • 평가이해관계자 파악 } \\
\text { • 평가대상 분석 } \\
\text { • 평가의 목적 및 범위 설정 } \\
\text { • 평가 방법론 제시 }\end{array}$ \\
\hline $\begin{array}{l}\text { 평가수행(Conducting)의 } \\
\text { 일관성(Consistency) 및 } \\
\text { 투명성(Transparency) }\end{array}$ & 수행 단계 & $\begin{array}{l}\text {-국내 문헌 및 자료 조사 } \\
\text { • 현지조사 계획 및 수행 } \\
\text { - 조사내용 분석 수행 } \\
\text { - 평가자의 태도 및 윤리준수 }\end{array}$ \\
\hline $\begin{array}{l}\text { 평가결과(Results)의 } \\
\text { 신뢰성(Credibility) }\end{array}$ & 결과 보고 단계 & $\begin{array}{l}\text { - 평가결과의 객관성 제시 } \\
\text { - 평가제언의 유용성 검토 } \\
\text { - 보고서 작성의 성실성 }\end{array}$ \\
\hline
\end{tabular}

평가품질관리 기준을 마련함으로써, 평가보고서의 품질을 높일 수가 있고, 품질을 높임으로 써 평가에 대한 신뢰성을 확보할 수 있다. 신뢰성을 확보할 때 조직원들의 학습목적을 증진시킬 수가 있으며 궁극적으로는 환류(Feedback)를 활성화 할 수 있다. 이러한 선순환 구조로 평가의 기능이 강화될 수 있기 때문에 평가품질관리는 최근 주요 추진사항으로 강조되고 있었다.

\section{평가계획, 선정, 우선순위}

$\mathrm{KOICA}$ 는 연간 평가대상을 선정할 때, 정책연관성, 확대적용가능성, 유용성, 평가가능성, 비 용대비 타당성 등의 원칙하에 중점국, 중점분야, 중점이슈 등을 종합적으로 고려하여 선정한다. $\mathrm{KOICA}$ 의 전사적 기본방향과 부합하고, 분야별로 대표성이 있고, "평가성 사정(Evaluability Assessment) $)^{3}$ '에서 평가결과가 높은 사업 중에서 선정한다. DAC Peer Review 가이드라인 에 따르면 연간평가 대상을 선정하는 과정이 투명하고 체계적인지를 점검하는데, $\mathrm{KOICA}$ 의 경 우 전략적으로 이루어진다고 할 수 있다. 1차적으로 연간평가대상 범위를 선정하고, 2 차적으로

2) The DAC Qaulity Standards for Development Evaluation, OECD/DAC

3) 평가성 사정(Evaluability Assessment) 제도 : (1) 사업 개입논리의 명확성, (2) 사업 설계 성과의 지향성,

(3) 사업 성과의 측정 가능성, (4) 사업 성과의 도출시점, (5) 사업 모델로서의 확대가능성 등의 항목을

평가, '11년에 도입하여 '12년에 규정화 
$\mathrm{KOICA}$ 사무소 및 관련부서를 대상으로 평가대상수요를 접수하고, 3차적으로 평가실 직원들의 평가성 사정작업이 이루어진다. 4차적으로는 KOICA 내부의 평가심의위원회가 개최되며, 최종 적으로 총리실 통합평가 소위를 통해 확정된다.

2011년도부터 새롭게 도입한 평가성 사정(Evaluability Assessment) 제도는 평가기능이 강 화되면서 더욱 체계적으로 도입되었다고 할 수 있다. $\mathrm{KOICA}$ 의 경우, 연간 프로젝트 사후평가 후보로 평균 130 건의 대상이 파악되고 있으나, 평가실 인력, 예산, 관리정도 등을 감안하였을 때 실질적으로는 $10 \%$ 내외인 12 건 정도를 사후평가로 수행하고 있다. 효과적으로 평가대상의 우선순위를 확인할 필요가 있다.

【KOICA 연간 평가대상선정 기준】

\begin{tabular}{|c|c|c|}
\hline \multirow{2}{*}{ 평가 종류 } & 대상선정기준 세부(안) & \\
\hline & KOICA & 주기 \\
\hline 국별종합평가 & $\begin{array}{l}\text { (1) KOICA 중점협력국 대상 } \\
\text { (2) 대륙별·지역별 배분 고려 } \\
\text { (3) CPS 수립주기 고려 }\end{array}$ & 매5년 \\
\hline $\begin{array}{l}\text { 분야별 } \\
\text { 종합평가 }\end{array}$ & $\begin{array}{l}\text { (1) KOICA 중점분야(5대분야) 대상 } \\
\text { (2) 분야별 세부 프로그램 분류 고려 }\end{array}$ & 매3년 \\
\hline $\begin{array}{c}\text { 사업형태별 } \\
\text { 평가 }\end{array}$ & (1) 주기적 · 종합적 점검필요성이 높은 사업형태 위주 & 매3년 \\
\hline $\begin{array}{l}\text { 프로젝트 } \\
\text { 사후평가 }\end{array}$ & $\begin{array}{l}\text { (1) 1차선정: 종료평가 수행 후 2년 4년 이내 사업 } \\
\text { (2) 2차선정: } 200 \text { 만불 이상 규모사업 위주 } \\
\text { (3) 3차 선정: 수요조사 및 평가성 사정 }\end{array}$ & 매년 \\
\hline 주제별 평가 & $\begin{array}{l}\text { (1) 내부 또는 외부의 특별수요 요청발생 시 } \\
\text { (2) 개발 이슈, 주요현안사항 위주 고려 } \\
\text { ※ 단, 수혜자 만족도 평가는 기관평가 제출용으로 매년 } \\
\text { 실시 }\end{array}$ & $\begin{array}{l}\text { 수요 } \\
\text { 발생시 }\end{array}$ \\
\hline $\begin{array}{l}\text { 프로젝트 } \\
\text { 중간/ } \\
\text { 종료평가 }\end{array}$ & $\begin{array}{l}\text { 프로젝트/프로그램 사업 전체 } \\
\text { ※ 단, 1) 아래에 해당하는 사업은 중간평가 생략 가능하며 } \\
\text { - 개발조사사업 } \\
\text { - 사업규모가 } 100 \text { 만불 미만 또는 사업기간이 2년 } \\
\quad \text { 미만인 사업 } \\
\text { - 기자재 지원 비율이 총사업규모의 } 50 \% \text { 이상인 사업 } \\
\text { 2) 개발조사사업의 종료평가는 보고서 심사로 대체 }\end{array}$ & $\begin{array}{l}\text { 사업계획 } \\
\text { 근거 }\end{array}$ \\
\hline
\end{tabular}




\section{공동평가}

$\mathrm{DAC}$ 는 상호 학습을 강화하는 차원에서 공동평가를 장려하고 있다. 최근에는 수원국의 평가 역량강화를 위해 수원국과 공동평가를 더욱 장려하고 있는 추세이다. $\mathrm{KOICA}$ 의 경우는 국내 · 외적으로 다양하게 공동평가를 실시해 왔다. 선진기관과 공동평가는 GTZ와 실시하였고, 국내 적으로는 2011년 농식품부와 농촌분야 공동사업, 2012년 $\mathrm{EDCF}$ 와 대조평가를 실시해왔다. 협 력대상국과는 콜롬비아와 중미지역 사업의 평가를 사전형성 단계부터 공동으로 수행하고 있다.

\section{평가문화 확산}

$\mathrm{KOICA}$ 는 중기전략에 따라 대내외 파트너쉽 제고와 평가인식 제고를 위하여 2011년부터 (1) 개발평가 세미나 개최 및 참석, (2) 개발평가 교육 (3) 관련책자 발간 (4) 정보공개활동 등을 통해 단내외 평가문화 공유 및 확산을 추진하여 왔다. 평가세미나의 경우, 주제 및 목적에 따라 단내 참여용과 단내외 참여용으로 이루어지는데, 평균 30 40명에 이르는 평가관련 외부기관, 평가 자, 학계, 관심 대학생, 전문가 등이 다양하게 참여해 왔으며 세미나를 통해서 개발평가에 대한 관심이 증대되는 효과를 거두고 있었다.

\section{【KOICA 세미나 개최 현황 】}

\begin{tabular}{c|c}
\hline 구분 & 내용 \\
\hline \multirow{5}{*}{ 세미나 } & - 2011년도 1-4차 개발평가세미나 개최 \\
& -1 차 : 개발 평가 설계 품질 강화 방안(3.30) \\
& -2 차 : 개발평가의 현지조사 설계 및 수행 방법(6.14) \\
& -3 차 : 원조사업 성과관리(8.25) \\
& -4 차 : 영향평가의 정책적 함의와 수행(12.22) \\
& -2012년도 1-4차 개발평가세미나 개최 \\
& -1 차 : DAC Evalnet 평가네트워크 이슈 공유(4.20) \\
& -2 차 : 개발평가 품질관리(6.15) \\
\hline
\end{tabular}

\section{평가 정보공개 및 환류}

$\mathrm{KOICA}$ 는 모든 평가보고서를 $\mathrm{KOICA}$ 및 $\mathrm{OECD} / \mathrm{DAC}$ 홈페이지에 게시하고 있다. DAC에서 는 정보의 접근성과 공개여부를 점검하고 적극적으로 권장하고 있는데, $\mathrm{KOICA}$ 의 경우 평가보 고서등은 2006년부터 국 · 영문 보고서를 공개해오고 있었다. 또한 2012년도부터는 평가정보 
의 접근성을 강화하기 위하여 전년도 평가결과요약을 포함한 국 · 영문 연보를 발간하고 있다. 평가결과 환류를 위해서는 연간 평가보고서의 제언 및 결과를 종합하여 관련부서에 의무적으로 과제화하여 수행하는 평가결과환류(Feedback) 제도를 운용하고 있다. 2011년의 경우 총 7건의 평가로 24 건의 후속조치 과제가 도출되어 수행되었다.

\section{【KOICA 평가결과 전략 환류 사례】}

\begin{tabular}{|c|c|c|}
\hline 2008년 & 2009년 & 2010년 \\
\hline $\begin{array}{l}\text { 1. 국별지원전략 (CPS) 수립 } \\
\text { 2. 사업발굴체계 개선 } \\
\text { 3. 성과측정 지표 설정 } \\
\text { 4. 사업관리시스템 구축 }\end{array}$ & $\begin{array}{l}\text { 1. KOICA 선진화계획 수립 } \\
\text { 2. 사업수행 개선안 수립 } \\
\text { 3. 현장중심 사업 수행을 위한 } \\
\text { 지역별 조직 편제로 개편 }\end{array}$ & $\begin{array}{l}\text { 1. 유무상 CPS 통합원조전략 } \\
\text { 마련을 위한 통합회의 실시 } \\
\text { 2. 패키지 형태 프로그램 수립 } \\
\text { 3. 국가 원조브랜드 개발 } \\
\text { 4. 국별연수 모델 수립 } \\
\text { 5. 현지화된 입찰방법 개발 }\end{array}$ \\
\hline
\end{tabular}

\section{4. 이슈 및 향후과제}

$\mathrm{KOICA}$ 차원에서 개발평가분야는 다방면으로 지속적인 개선이 이루어졌다고 할 수 있다. 평 가 전략이 신규로 수립되었으며, 평가실 독립을 통해 독립성을 절차상으로 확보하려고 하였으 며, 품질관리 확보와 대 - 내외 파트너쉽 제고노력 등이 바로 그러한 개선사항에 해당한다고 할 수 있다. 반면, 평가분야에 있어서 $\mathrm{KOICA}$ 가 향후 장기적으로 개선해야할 과제는 여러가지가 있다. 예를 들어 공여국간 공동조사 및 공동분석 등은 향후 원조조화라는 측면에서 KOICA도 강화해야할 부분일 것이다. 또한 경영진들의 평가결과에 대한 대응체계(Management Response System) 구축이 필요할 것이다. 왜냐하면 평가결과를 조직이 전략적으로 활용하고 경영진의 의지가 있는지를 나타내는 중요한 척도이기 때문이다. JICA, ADB 등 여타기관들이 평가보고서에 해당부서의 검토의견을 함께 기재하고 정책적 사항은 정책결정자들의 동의여부 를 투명하게 공개하는 것은 기관의 개선의지를 표명한다는 측면에서 매우 중요한 평가결과 환 류단계이기 때문이다. 
단기적으로 $\mathrm{KOICA}$ 가 개선해야 할 부문은 수원국의 평가 역량강화와 역할 확대이다. $\mathrm{KOICA}$ 사업 전반적인 과정에서 수원국을 참여시켜 사전, 중간, 종료, 사후 평가를 공동으로 수행할 필 요가 있다. 수원국 평가역량강화부분은 시도하려는 단계에 있지만 향후 우선적으로 도입해야하 는 부분이기도 하다. 현재 $\mathrm{KOICA}$ 는 프로젝트 사업의 종료평가시 수원국과 공동으로 평가를 수 행하도록 의무화하고 있다. 초기단계는 사업단계에서 참여를 시키지만, 궁극적으로는 정책대화 와 전략형성과정에서부터 수원국의 평가 역량강화를 고려하여 참여를 활성화 시킬 수가 있다. 이는 수원국의 주인의식 함양과 함께 상호책임성 강화, 부가적으로 $\mathrm{KOICA}$ 사업의 성과입증 부 담 경감까지 이어질 수 있기 때문에 우선적으로 진행되어야하는 개선사항이다.

또한 평가품질강화는 지속적으로 강화해야한다. 타 공여기관의 경우 평가수행의 양보다는 소 수의 평가수행을 통한 신뢰성있는 보고서 발간을 더욱 중점적으로 추진하고 있다. 예를 들어 호 주의 원조기관인 AusAID의 경우, 연간 발간보고서는 평균 3건에 불과하지만 원조효과성에 대 한 연례보고서 등 보다 깊이 있고 파급효과가 지대한 이슈들만 선택적으로 발간하고 있다. 비록 2011년도부터 KOICA에서는 평가품질을 위해 노력해왔지만 평가품질에 영향을 미치는 여러 요인들이 존재하기 때문에 보다 향후 지속적으로 강화시켜야할 것이다.

\section{5. 시사점 및 결론}

한국의 DAC Peer Review의 최종결과는 12 월 이후 공개될 예정이므로 평가분야의 최종 결 론이 어떻게 나타날지는 미정인 상태이다. 그렇지만 DAC Peer Review를 계기로 KOICA 차 원에서는 평가분야의 진전사항 및 개선사항을 정리하고 4년 후 DAC Peer Review준비를 위해 어떠한 요소들을 점검하고 강화해야하는지를 파악하는 기회가 되었다. 지속적인 개선노력과 $\mathrm{DAC}$ 평가네트워크(Evalnet) 등과 활발한 교류를 통해서 향후 국제적 기준에 부합하는 평가체 계를 갖출 수 있을 것으로 예상된다.

한편으로, 본 글에서 다루지 않았지만 "원조를 넘어선 개발(Development Beyond Aid)" 측 면과 "원조효과성 및 성과(Aid Effectiveness and Results)" 측면에서 평가기능은 향후 더욱 중요하게 다루어질 것으로 예측된다. 조직내부의 개별 사업단위의 모니터링과 평가체계 이상으 로 거시적이고 보다 실질적 개발성과 측정여부, 점검여부, 관리 여부 등이 $\mathrm{DAC}$ 회원국으로서 더욱 강조될 것이다. DAC에서 권고하고 있는 개발성과관리(Management for Development 
Results, MfDR)에 입각한 성과관리, 협력대상국 참여 및 관리, 성과에 입각한 프로그래밍, 인 센티브, 성과틀(Results Framework) 활용 등은 원칙적으로 평가부문에서 변화라기보다는 원 조수행체계의 근본적인 변화에 의해서 가능하다. 따라서 4 년 이후를 대비한다면 개발성과측정 을 위한 평가기능의 전환과 함께 측정을 가능케 하는 수행환경에 대한 변화도 함께 준비하여야 한다. 